\title{
Supplementation with vitamin E does not alter plasma leptin, adiponectin or corticosterone response to different high-fat diets in rats*
}

\author{
E. Fürstenberg ${ }^{1}$, K. Lachowicz, E. Olczak, M. Stachoń, \\ D. Rosołowska-Huszcz and J. Gromadzka-Ostrowska \\ Warsaw University of Life Sciences ( $S G G W)$, \\ Department of Dietetics, Faculty of Human Nutrition and Consumer Sciences \\ Nowoursynowska 159c, 02-776 Warsaw, Poland
}

(Received 8 July 2008; revised version 18 March 2009; accepted 24 June 2009)

\begin{abstract}
The aim of the study was to assess if supplementation of high-fat diets with vitamin E influences circulating leptin, adiponectin and corticosterone (Cs) in rats. Forty-eight male rats were divided into 4 groups of 12 rats each, and for 6 weeks fed on $20 \%$ (wt/wt)-fat diets. Dietary fat was provided by cod liver oil (CLO), grape seed oil (GO), rape seed oil (RO), or lard (L), enriched with vitamin $\mathrm{E}(500 \mathrm{mg} / \mathrm{kg},+\mathrm{E})$, or not. Plasma hormone levels were unaffected by vitamin E supplementation. Corticosterone concentrations were, however, higher in $\mathrm{RO}+\mathrm{E}$ rats compared with non-supplemented RO rats. Fat type had a significant impact on relative plasma adipokine levels, body weight, and body fatness. Specifically, GO and RO exhibited the highest levels of adipokines. Yet, plasma Cs levels did not vary among groups. Our study supports the preventive role of vegetable fats, even if supplied in excess, against adipose tissue deposition and its ramifications in terms of hormone secretion.
\end{abstract}

KEY WORDS: fatty acids, adipose tissue, leptin/adiponectin ratio, vitamin E, adrenals, body composition, rats

\section{INTRODUCTION}

Energy homeostasis is a result of the balance between energy intake and expenditure, and is regulated centrally by the brain. The brain cortex, brain stem, and hypothalamus integrate a myriad of afferent neural, metabolic and hormonal

\footnotetext{
* Supported by the Polish Ministry of Science and Higher Education, Grant No. 2 P06T 03127

${ }^{1}$ Corresponding author: e-mail: ewa_furstenberg@sggw.pl
} 
signals that indicate the nutritional status of the organism. Efferent pathways accordingly modulate feeding behaviour, physical activity, and cellular metabolism (Orlando et al., 2005). This control system has evolved to operate with remarkable precision. It breaks down, however, under conditions prevailing in the modern era, with a sedentary lifestyle and easy availability of palatable and calorically dense food. It is mirrored in epidemic proportions of overweight and obesity affecting a worrisome percentage of adult and young populations worldwide (Woods et al., 2004).

Several lines of evidence support the fundamental role of adipokines: leptin and adiponectin in this crosstalk. Like glucocorticosteroids (GCs), these adipokines modulate energy metabolism through an interaction with both hypothalamic and peripheral mechanisms (Ahima and Osei, 2001). Leptin and adiponectin suppress appetite and increase energy expenditure by raising sympathetic tone and enhancing cellular glucose and fatty acid utilization (Woods et al., 2004). GCs act counterregulatorily to adipokines in terms of hypothalamic mechanisms of energy balance regulation (Ishida-Takahashi et al., 2004).

In recent years, knowledge about the cellular actions of nutrients has dramatically expanded and it has become apparent that fatty acids (FAs) fulfill a critical regulatory function through direct activation or inhibition of genes (Drevon, 2005). While modulation of leptin and GCs synthesis by FAs has been extensively studied (Stachoń et al., 2003; Ukropec et al., 2003; Drevon, 2005, 2006; Flachs et al., 2006), information on the effects of nutrition on adiponectin secretion is rather limited. Trials that have investigated the acute effects of a change in dietary lipid composition have shown a decrease in adiponectin secretion or no response (Peake et al., 2003). Little is yet known about fat-induced modifications of adiponectin expression and release in the long run.

Generally, polyunsaturated fatty acids (PUFAs) have been shown to prevent obesity, cardiovascular diseases and insulin resistance in rodents fed on highfat diets. Feeding fish oil itself has been shown to decrease the formation of proinflammatory F2-isoprostanes, markers of oxidative stress (Saraswathi et al., 2007). In addition, n-3 FAs are known to up-regulate the activities of antioxidant enzymes in a tissue-independent fashion and to an extent inversely related to the feeding level (Bhattacharya et al., 2003).

On the other hand, overconsumption of highly unsaturated fatty acids results in a high degree of unsaturation in membrane phospholipids. This may, in turn, be conducive to increased and rapid lipid peroxidation, cholesterol oxidation, and membrane damage. As a corollary, secretion of adrenal and/or adipocyte-derived hormones may be disregulated when associated with insufficient nutritional antioxidative protection (Furukawa et al., 2004). 
The potential risk of damage to macromolecules from excessive oxidative stress is especially high in steroidogenic cells, which use molecular oxygen for steroid biosynthesis and exhibit high rates of generation of free radicals and peroxides (Abidi et al., 2004). As shown by the exposure of adipocytes (Fasshauer et al., 2002) and adrenal cells (Abidi et al., 2004) to a prooxidative milieu, oxidative stress adversely affects hormone expression and secretion.

Vitamin $\mathrm{E}$ is a powerful antioxidant sequestered in the hydrophobic interior of membranes. It acts as a chain-breaking agent to quench lipid peroxidation and help to maintain the integrity of biological membranes (Wang and Quinn, 1999).

Therefore, this paper had as its objective to test the hypothesis that supplementation of high-fat diets with vitamin E, a potent antioxidant, exerts a positive impact on secretion of leptin, adiponectin and/or corticosterone in mature rats.

\section{MATERIAL AND METHODS}

\section{Animals and diets}

The experimental protocol was approved by the Local Animal Care and Use Committee. The experiment was carried out on 48 male Wistar rats with initial body weights of $210 \pm 8 \mathrm{~g}$. The animals were provided by the Kielanowski Institute of Animal Physiology and Nutrition (Jabłonna, Poland). The rats were housed in individual stainless-steel cages under controlled conditions of temperature $\left(22 \pm 1^{\circ} \mathrm{C}\right)$, humidity (50-60\%) and light (12-12-h light-dark cycle). Upon arrival, the rats began to be fed Labofeed H (Laboratory Animal-Feed Plant, Kcynia, Poland) ad libitum. After a one-week adaptation period, they were randomly divided into four groups (12 rats each) and assigned to one of four semisynthetic high-fat diets $(20 \% \mathrm{w} / \mathrm{w})$ for six weeks. Dietary fat was supplied by cod liver oil, CLO; grape seed oil, GO; rape seed oil, RO; or lard, L (Table 1). Six rats from each dietary group were fed the respective high-fat diet enriched with vitamin E ( $\alpha$-tocopherol acetate, $500 \mathrm{mg} / \mathrm{kg}$ ). The diets were prepared according to a formula elaborated by Gronowska-Senger and Pierzynowska (2002), but their fat content was modified. The animals had free access to tap water and feed throughout the experiment. Feed intake, corrected for spillage, was measured daily for each animal and body weights were determined every three days. At the end of the experiment, the rats were deprived of feed for $12 \mathrm{~h}$, euthanized and exsanguinated by cardiac puncture. Blood was then centrifuged and stored at $-80^{\circ} \mathrm{C}$. Eviscerated carcasses were frozen for subsequent analyses of body composition. 
Table 1. Chemical composition and metabolizable energy of experimental diets

\begin{tabular}{lcccc}
\hline \multirow{2}{*}{ Item } & \multicolumn{4}{c}{ Dietary $^{\text {group }}{ }^{1}$} \\
\cline { 2 - 5 } & CLO & GO & RO & L \\
\hline Protein, \% & 13.54 & 14.41 & 14.38 & 13.91 \\
Fat, \% & 36.46 & 38.49 & 32.00 & 38.75 \\
Carbohydrates, \% & 50.00 & 47.15 & 53.62 & 47.38 \\
\% of fat & & & \\
$\quad \sum$ SFAs & 18.56 & 10.68 & 8.77 & 40.63 \\
$\sum$ MUFAs & 43.60 & 19.98 & 54.58 & 48.64 \\
$\sum$ PUFAs & 33.02 & 70.25 & 36.00 & 9.07 \\
n-3 PUFAs & 22.31 & 0.5 & 8.53 & 0.64 \\
n-6 PUFAs & 10.18 & 69.75 & 27.47 & 8.43 \\
ME, MJ/kg & 21.12 & 21.38 & 20.44 & 21.42 \\
\hline
\end{tabular}

${ }^{\top} \mathrm{CLO}$ - cod liver oil, GO - grape seed oil, RO - rape seed oil, L - lard

Quantification of hormones in plasma, chemical composition of diets and fat content in carcasses

Concentrations of plasma leptin, adiponectin and corticosterone were measured with commercially available ${ }^{3} \mathrm{H}$-labelled corticosterone, ${ }^{125} \mathrm{I}$-labelled leptin, and ${ }^{125}$ I-labelled adiponectin radioimmunoassay (RIA) kits (Linco Research Inc., USA and DSL, USA, respectively).

The composition of experimental diets was determined in the National Food and Nutrition Institute (Warsaw, Poland), and detailed analyses of fatty acid composition of fats used in diets were performed by means of the AOCS $\mathrm{Ce}$ 2-66 method at the Institute of Chemical Industry (Warsaw, Poland).

Body fat content was established in triplicate samples of autoclaved and homogenized carcasses by the Soxhlet method, with diethyl ether as the eluent.

\section{Statistical analyses}

Whenever necessary, data were log-transformed to approximate a normal distribution. The data were evaluated by two-way analysis of variance (ANOVA) for the effects of fat type and vitamin E supplementation, followed by a post-hoc Fisher's LSD test to determine individual differences between means. In all measurements, when there was no differential effect of a factor, the two treatments were combined and the impact of a significant factor was analysed. Correlations between plasma adipokine concentrations (absolute values and values adjusted for body fat) and body parameters, as well as between plasma adipokine concentrations and nutrient intakes, were analysed by the linear regression method. $\mathrm{P}<0.05$ was adopted as the threshold of significance. Values are reported as means $\pm \mathrm{SE}$. All calculations were performed with StatgraphicsPlus 4.1 for Windows (Statpoint, USA). 


\section{RESULTS}

Final body weight and body fat mass. Final body weights (FBW) and body fat mass (FM) are given in Table 2. Both parameters depended on dietary fat type $(\mathrm{P}<0.00001$ for all parameters) and were markedly higher in group $\mathrm{L}$ than in the other groups. Moreover, the RO group did not differ from the GO group with respect to FBW and FM, but the FM of the CLO group was significantly higher than that of GO and RO groups.

Table 2. Final body weight (FBW), fat mass (FM) and intake of feed, energy, fat, saturated fatty acids (SFAs), monounsaturated fatty acids (MUFAs) and polyunsaturated fatty acids (PUFAs)

\begin{tabular}{|c|c|c|c|c|c|c|c|c|c|}
\hline \multirow{3}{*}{\multicolumn{2}{|c|}{ Variables }} & \multicolumn{8}{|c|}{ Dietary group $^{1}$} \\
\hline & & \multicolumn{2}{|c|}{ CLO } & \multicolumn{2}{|c|}{ GO } & \multicolumn{2}{|c|}{ RO } & \multicolumn{2}{|c|}{$\mathrm{L}$} \\
\hline & & mean & SE & mean & SE & mean & SE & mean & SE \\
\hline FBW g & & $253.4^{\mathrm{a}}$ & 8.2 & $238.2^{\mathrm{a}}$ & 9.4 & $238.2^{\mathrm{a}}$ & 10.3 & $302.4^{\mathrm{b}}$ & 8.7 \\
\hline FM g & & $19.9^{\mathrm{b}}$ & 2.3 & $12.4^{\mathrm{a}}$ & 1.1 & $12.8^{\mathrm{a}}$ & 1.5 & $31.5^{\mathrm{c}}$ & 2.9 \\
\hline \multicolumn{10}{|c|}{ Intake $/ 100 \mathrm{~g} \mathrm{FBW}$} \\
\hline energy, M & & $0.086^{\mathrm{b}}$ & 0.0065 & $0.091^{\mathrm{b}}$ & 0.0052 & $0.115^{\mathrm{c}}$ & 0.0083 & $0.050^{\mathrm{a}}$ & 0.0028 \\
\hline fat, $g$ & & $0.30^{\mathrm{b}}$ & 0.033 & $0.33^{\mathrm{b}}$ & 0.030 & $0.45^{\mathrm{c}}$ & 0.049 & $0.15^{\mathrm{a}}$ & 0.013 \\
\hline SFAs, $\mathrm{g}$ & & $0.026^{\mathrm{a}}$ & 0.0029 & $0.036^{\mathrm{b}}$ & 0.0032 & $0.084^{\mathrm{d}}$ & 0.0091 & $0.060^{\mathrm{c}}$ & 0.0053 \\
\hline MUFAs, g & & $0.165^{\mathrm{b}}$ & 0.018 & $0.064^{\mathrm{a}}$ & 0.006 & $0.196^{\mathrm{b}}$ & 0.021 & $0.071^{\mathrm{a}}$ & 0.006 \\
\hline \multirow{3}{*}{ PUFAs, $\mathrm{g}$} & $\Sigma$ & $0.109^{\mathrm{b}}$ & 0.012 & $0.234^{\mathrm{d}}$ & 0.021 & $0.149^{\mathrm{c}}$ & 0.016 & $0.013^{\mathrm{a}}$ & 0.001 \\
\hline & $n-3$ & $0.026^{\mathrm{c}}$ & 0.0028 & $0.002^{\mathrm{b}}$ & 0.0001 & $0.093^{\mathrm{d}}$ & 0.003 & $0.001^{\mathrm{a}}$ & 0.0001 \\
\hline & $n-6$ & $0.083^{\mathrm{c}}$ & 0.009 & $0.231^{\mathrm{d}}$ & 0.021 & $0.006^{\mathrm{a}}$ & 0.011 & $0.012^{\mathrm{b}}$ & 0.001 \\
\hline
\end{tabular}

different ${ }^{a, b, c, d}$ letters indicate significant differences between dietary groups $(\mathrm{P} \leq 0.05)$; results are expressed as mean \pm standard error (SE); ${ }^{1} \mathrm{CLO}$ - cod liver oil, GO - grape seed oil, RO - rape seed oil and L - lard

Intake of feed, energy, fat and fatty acids. The total feed, energy and dietary fat intakes (Table 2) were affected by dietary fat composition $(\mathrm{P} \leq 0.0001)$ and were the highest in group RO and the lowest in group L. Additionally, all of these parameters were greater in $\mathrm{RO}$ rats than in GO animals, and did not differ significantly between groups CLO and GO.

The profile of fatty acid intake was highly differentiated between dietary groups $(\mathrm{P}<0.00001)$. Saturated fatty acid $(\mathrm{SFA})$ and $\mathrm{n}-3$ polyunsaturated fatty acid (PUFA) intakes were the highest in group RO and the lowest in groups L and CLO, respectively. Monounsaturated fatty acid (MUFA) consumption in groups CLO and RO exceeded that in the two other groups. The highest total PUFA and n-6 PUFA intakes were observed in group GO. Animals of group L consumed significantly less PUFA, including n-3 PUFAs, than the other rats.

The intakes of feed, dietary fat and fatty acids, as well as FBW, BWG and FM 
were not detectably affected by vitamin E supplementation.

Plasma hormone concentrations. Since body fat mass varied among three of the four dietary groups, we normalized adiponectin and leptin concentrations for differences in body fat content to make them independent of diet-induced differences in adipose tissue mass. Thus, levels of the hormones were expressed per $\mathrm{g}$ of body fat. Analysis of plasma hormone concentrations showed a significant effect of dietary fat type on relative plasma leptin and adiponectin levels $(\mathrm{P}<0.002$ and $\mathrm{P}<0.0001$, respectively). In contrast, plasma hormone concentrations were generally unaffected by vitamin E supplementation. Specifically, plasma leptin and adiponectin responded to dietary modifications in parallel (Figure 1). Groups $\mathrm{GO}$ and RO exhibited the highest levels of the hormones, while adiponectin and leptin levels observed in CLO rats were significantly lower than in GO and RO rats, but markedly higher than levels in rats fed the high-lard diet. Strikingly, unlike adipokines, plasma Cs levels did not vary among groups, despite feeding the animals on diets with different FA composition (Figure 2B). Admittedly, we observed a tendency towards smaller circulating Cs in RO group, but the difference failed to reach statistical significance. An interaction between fat type and vitamin E was, however, discovered for plasma Cs levels $(\mathrm{P}<0.04)$, with Cs concentrations being markedly higher in rats fed on the rape seed oil diet enriched with vitamin E compared with non-supplemented RO rats.

These effects were accompanied by significant positive correlations between leptin and growth parameters (FBW, $\mathrm{r}=0.30, \mathrm{P} \leq 0.05$, and $\mathrm{FM}, \mathrm{r}=0.47, \mathrm{P}<0.005$ )
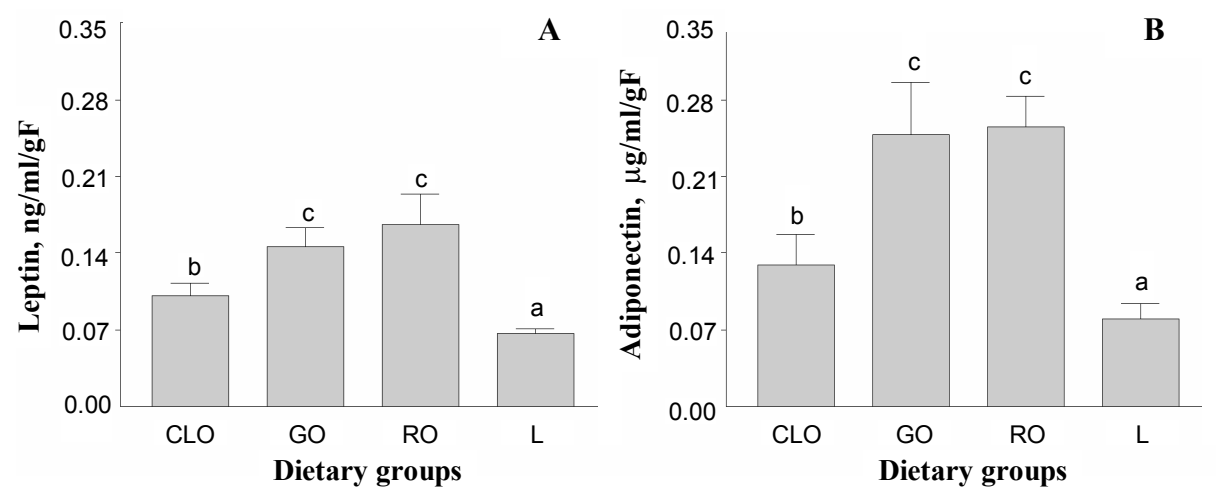

Figure 1. Plasma leptin (ng/ml/g F) - panel A and adiponectin $(\mu \mathrm{g} / \mathrm{ml} / \mathrm{g} \mathrm{F})$ - panel B concentrations in rats fed diets containing $20 \%(\mathrm{w} / \mathrm{w})$ cod liver oil (group CLO), grape seed oil (GO), rape seed oil (group RO) or lard (group L) for six weeks. Values are expressed as the mean \pm pooled standard error (SE); different a, b letters indicate significant differences between groups CLO, GO, RO and $\mathrm{L}(\mathrm{P} \leq 0.05) ; \mathrm{F}$ - body fat 
and between plasma $\mathrm{Cs}$ and $\mathrm{FM}(\mathrm{r}=0.34, \mathrm{P}<0.05)$ across all animals. No respective associations were, however, demonstrated for plasma adiponectin. On the other hand, plasma adiponectin and $\mathrm{Cs}$ were associated with energy intake $(\mathrm{r}=0.32$, $\mathrm{P}<0.05$ for adiponectin and $\mathrm{r}=-0.30, \mathrm{P} \leq 0.05$ for $\mathrm{Cs})$ and fat intake $(\mathrm{r}=0.34, \mathrm{P}<0.04$ for adiponectin and $\mathrm{r}=-0.40, \mathrm{P}<0.01$ for $\mathrm{Cs}$ ). Plasma adiponectin and $\mathrm{Cs}$ were also related to $n-3$ PUFAs intakes $(r=0.40, P<0.02$ for adiponectin and $r=-0.30$, $\mathrm{P}<0.05$ for Cs). Finally, plasma Cs tended to inversely correlate with MUFAs intake. Neither significant associations nor trends were found between plasma leptin or energy and nutrient intakes.

Plasma hormones were not intercorrelated except for relative leptin and Cs $(\mathrm{P}<0.02, \mathrm{r}=-0.41)$, as well as relative adiponectin and leptin $(\mathrm{P}<0.0001, \mathrm{r}=0.77)$.

\section{DISCUSSION}

This study attempted to uncover the impact of excess fat of different FA composition on circulating plasma adiponectin, leptin and Cs. Bearing in mind the prooxidative properties of FAs and susceptibility of adrenocortical cells and adipocytes to lipid peroxidation (Abidi et al., 2004; Furukawa et al., 2004), we hypothesized that supplementation with vitamin $\mathrm{E}$ of high-fat diets with diverse proportions of FAs varying in unsaturation degree could favourably modify secretion of Cs, leptin and/or adiponectin, especially in rats fed on the high PUFA diets.

Contrary to our prediction, this study indicated that, irrespective of the source of dietary fat, vitamin $\mathrm{E}$ had no effect on hormone concentrations in rats reared on high-fat diets for six weeks. The exceptions were Cs levels in RO+E group, which surprisingly exceeded values observed in non-supplemented $\mathrm{RO}$ rats $(\mathrm{P}<0.04$ for fat type $\mathrm{x}$ vitamin $\mathrm{E}$ effect).

There is no consensus as to the links between oxidative stress induced by dietary fat, antiooxidative mechanisms and secretory functions of adipocytes. On the one hand, Soares et al. (2005) showed that adipocytes are highly vulnerable to oxidative stress induced by hydrogen peroxide with a subsequent marked decrease in adiponectin secretion. In vitro observations were confirmed by Katsuki et al. (2006) who indicated that systemic enhancement of oxidative stress correlates with diminished circulating levels of adiponectin in men. On the other hand, Drevon (2005) demonstrated that supplementation with a mixture of antioxidants does not modify the effect exerted by n-3 PUFAs on plasma leptin levels in men. These observations lend indirect support for the results of the current study.

Additionally, adrenals chronically subjected to elevated levels of oxidative stress are at a high risk of steroidogenesis being markedly compromised. Tissues like adrenals are, however, especially well equipped with a variety of antioxidant 
defenses, both chemical and enzymatic. Consequently, oxidative damages of adrenocortical membranes during aging ultimately result in a marked decline of Cs production (Abidi et al., 2004).

There is ample evidence that dietary fats high in PUFAs induce greater oxidation and destruction of the requirements for vitamin $\mathrm{E}$ in rats to compensate for the higher oxidative stress imposed (Garrido et al., 1989). However, in the present study vitamin E-non-supplemented groups tended to have higher Cs concentrations than supplemented groups. Our results are thus at variance with previous observations. It is possible that non-supplemented diets provided the rats with sufficient amounts of antioxidants, and that supplementation with vitamin $\mathrm{E}$ proved to be of no functional importance. The indirect support for this idea may come from plasma vitamin E concentrations (data not shown) that were increased in supplemented rats only by $70-100 \%$ as compared with non-supplemented animals despite 16-24 fold differences in relative daily intake of vitamin $\mathrm{E}$ (the difference for L rats was 1325-fold). Rather, vitamin E supplementation impaired Cs secretion or its peripheral metabolism, as inferred from slightly lower Cs concentrations in rats supplied with vitamin $\mathrm{E}$.

With respect to the steroidogenic activity of adrenals, we presume that RO rats were subjected to a higher level of oxidative stress than the other dietary groups, which resulted in the impairment of Cs secretion. For, apart from a high content of unsaturated FAs, refined rape seed oil contains phytosterols including brassicasterol, a phytosterol not present in other commonly used vegetable oils, and some unique sulphur compounds such as thiocyanates, isothiocynates and nitriles. These compounds might interfere with vitamin $\mathrm{E}$ absorption or accelerate its depletion in tissues (Abidi et al., 2004). It appears plausible that supplementation of RO rats with dietary vitamin $\mathrm{E}$ improved antioxidative protection in adrenocortical cells and attenuated their response to the high PUFA burden. This points to vitamin E treatment being of therapeutic value in individuals with higher levels of oxidant stress.

There is a general consensus that dietary fat, in terms of both quantity and quality, affects circulating hormone concentrations. Leptin gene expression (in vitro) and leptin secretion (in vivo) are diminished and adiponectin expression and secretion are up-regulated by n-3 PUFAs (Ukropec et al., 2003; Drevon, 2005; Flachs et al., 2006; Saraswathi et al., 2007). Yet, up-regulation of leptin gene expression in rats fed on a high safflower oil diet, an abundant source of n-6 PUFAs, was also demonstrated by Takahashi and Ide (2000). SFAs bring about, in turn, hyperleptinaemia (Kim and Park, 2008) and hypoadiponectinaemia (Bueno et al., 2008). It is worth noting, however, that in most studies concentrations of leptin and adiponectin were expressed on an absolute basis without taking into account the disproportion in body fatness. In the current study, the pattern of differences in absolute concentrations of adiponectin 
resembled that found for plasma hormone levels expressed per $\mathrm{g}$ of body fat. In contrast, on an absolute basis, circulating leptin concentrations were similar in all dietary groups. However, plasma leptin and adiponectin levels adjusted for body fatness exhibited a similar response to high fat-diets with different fatty-acid profiles (Figures $1 \mathrm{~A}$ and B). Specifically, plasma levels of both adipokines were the highest in groups GO and RO, and surpassed these in rats fed on the CLO diet. Adipokine concentrations in CLO rats were, in turn, superior to plasma leptin and adiponectin concentrations in $\mathrm{L}$ rats. There was no respective difference between groups $\mathrm{RO}$ and $\mathrm{GO}$, despite remarkable differences in the intakes of specific FAs. First, RO rats consumed the highest amounts of SFAs. However, MUFAs and PUFAs dominated all fatty acids consumed by RO rats, and their n-3 PUFAs intake was the highest among all groups. Second, rats fed the GO diet consumed much less SFAs and MUFAs than RO rats, but much more PUFAs (the highest amounts among all groups), albeit n-6 PUFAs. On the other hand, L rats displayed low adiponectin levels, in accordance with the observations by Bueno et al. (2008). Presumably, this was due to very low consumption of PUFAs, especially n-3 (the lowest among all groups), and second highest SFA intakes (along with MUFAs, which dominated in the FAs profile). Taken together, these observations appear to suggest that PUFAs, irrespective of series, may up-regulate adiponectin and leptin secretion.

We also adjusted circulating leptin for adiponectin concentrations, i.e. calculated the leptin/adiponectin ratio (L/A, Figure 2A), an index believed to be a simple but excellent marker for insulin resistance and progression of arteriosclerosis (Oda et al., 2008). Generally, plasma adiponectin exceeded, on a numerical basis, the levels of leptin. However, the difference was more pronounced, albeit insignificantly, for RO and GO compared with CLO and L, resulting in lower
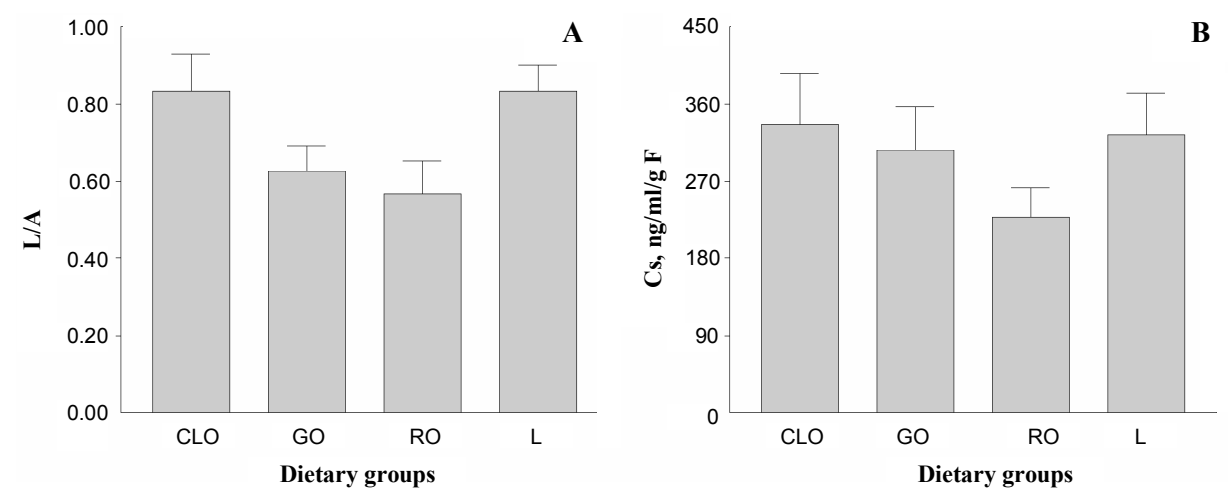

Figure 2. The ratio of leptin to adiponectin (L/A) - panel A and corticosterone (Cs) concentration $(\mathrm{ng} / \mathrm{ml})$ - panel B. Explanations see Figure 1 
L/A values in rats fed on diets based on vegetable oils and higher in rats fed on the animal fat diets. To the best of our knowledge, this is the first study that has addressed the association between L/A and fat type in high-fat diets. Yet, the difference in favour of GO and RO diets was not statistically significant, but we believe that any improvement in the L/A ratio could be of physiological and clinical importance.

With respect to corticosterone, Cs concentrations in $\mathrm{GO}$ and $\mathrm{RO}$ rats tended to be lower than in other groups, but the difference was not statistically significant. This observation is consistent with the previous study by Stachon et al. (2003) who demonstrated that differences in Cs concentrations present after 3 weeks of feeding high fat $(20 \% \mathrm{w} / \mathrm{w})$ diets with different FA profiles disappeared after another three consecutive weeks of dietary treatment. The effects of FAs on secretion of Cs may be also quantity-dependent, since Stachon et al. (2006) showed that sixweek feeding $40 \%$ (by weight) fat diets resulted in more than two-fold higher Cs levels in $\mathrm{L}$ rats than in $\mathrm{RO}$ animals. Lower plasma $\mathrm{Cs}$ in $\mathrm{GO}$ and $\mathrm{RO}$ rats could, at least to some extent, account for the increased circulating adiponectin observed in the current study in rats fed vegetable oil-rich diets, since Cs down-regulates adiponectin gene expression (Askari et al., 2005).

We found positive correlations between leptin concentrations and $\mathrm{BM}$ and between leptin concentrations and FM. They were not accompanied by any correlations between leptin levels and dietary intakes. Concomitant positive associations between adiponectin concentrations and intakes of feed, energy, fat and n-3 PUFAs in the present study suggest that mechanisms controlling the expression of genes for these two adipokines may be different. Along with the stimulatory effect of EPA and DHA on transcription of the gene and on corresponding plasma protein levels of adiponectin, but not leptin, observed in mice fed a high-fat diet by Flachs et al. (2006), these data point to the idea that, over the long term, circulating leptin reflects body fat reserves and may be only to a minor extent dependent on the direct action of dietary FAs.

The American Institute of Nutrition recommends that the maintenance diet for rodents contain $40 \mathrm{~g}$ fat $/ \mathrm{kg}$ (Reeves, 1997). The fat content in diets used in our study was set at $200 \mathrm{~g} / \mathrm{kg}$. It is well known that high-fat diets promote fat deposition and body weight gain in experimental animals and humans. However, not only the fat level but also the fat type, more specifically FA profile, can markedly impact body weight and body composition. In this respect, saturated and unsaturated, especially n-3 PUFAs, FAs are generally believed to act in opposite directions. Diets rich in SFAs augment the expansion of adipose tissue, while n-3 PUFAs and, to some extent, MUFAs exhibit protective properties (Ellis et al., 2002; Stachoń et al., 2006). As shown by Sadurskis et al. (1995) and Oudart et al. (1997) in rats fed on a high PUFA diet for 2-3 weeks, hyperplasia of brown adipocytes 
and up-regulation of UCP1 account for lower feed efficiency and hamper obesity development. In this respect, n-3 PUFAs display a higher potency than n-6 PUFAs (Takahashi and Ide, 2000). In contrast, diets rich in SFAs diminish UCP1 activity in BAT (Dube et al., 2002), promote adipocyte replication (Ellis et al., 2002) and induce adipocyte hypertrophy (Saraswathi et al., 2007).

In the present study the highest final body weights and adiposity were demonstrated in $\mathrm{L}$ rats in spite of their lowest relative intakes of feed, energy and fat. In contrast, rats reared on the RO diet had the highest relative feed, energy and fat consumption, while they presented the lowest final body weights among all experimental groups (however, not statistically different from CLO and GO rats). We also showed that treatment with the CLO diet caused increased adipose tissue deposition and a tendency towards a higher body weight compared with the GO diet, despite no differences in relative feed, energy and fat intakes between the groups. Such a phenomenon is quite intriguing, considering that the relative intake of SFAs was lower in CLO rats by approximately $40 \%$ and was accompanied by substantially higher (about thirteen-fold) n-3 PUFA intakes. However, GO rats consumed twice as much PUFAs as CLO rats. We speculate that PUFAs, even of the n-6 series, have overcome the effects of SFAs on tissue energy metabolism. Consequently, GO rats displayed lower energy efficiency compared to CLO rats. In this context, the lowest energy efficiency in RO-fed rats could be ascribed, surprisingly, to the highest relative n-3 PUFA intakes. Mechanistically, we presume that decreased energy efficiency in groups $\mathrm{GO}$ and $\mathrm{RO}$, inferred from the lower final body weights and higher consumption of PUFAs, could result from the adiponectin and leptin-driven upregulation of FA oxidation, both in BAT and skeletal muscles. Thus, our results reinforce several studies reviewed above, which demonstrated fatty acid-specific effects of high-fat diets on body weight gain and adiposity. The results of the present study attest also to the protective role of unsaturated fatty acids against accumulation of body fat.

\section{CONCLUSIONS}

In summary, our study adds to a growing body of data supporting the preventive role of vegetable fats, even in excess, against adipose tissue deposition in the body and, in the short run, its ramifications in terms of increased circulating leptin and adiponectin levels and decreased plasma corticosterone concentrations. Adequate intakes of dietary antioxidants provide efficacious protection against the deleterious effects of oxidative stress on hormone secretion associated with consumption of diets abundant in unsaturated fatty acids, of which a high-rape seed oil diet may augment requirements for vitamin $\mathrm{E}$. 


\section{ACKNOWLEDGEMENTS}

The authors are very grateful to Prof. J.S. Keller whose financial support was instrumental in determining plasma adiponectin concentrations.

\section{REFERENCES}

Abidi P., Leers-Sucheta S., Azhar S., 2004. Suppression of steroidogenesis and activator protein-1 transcription factor activity in rat adrenals by vitamin $\mathrm{E}$ deficiency-induced chronic oxidative stress. J. Nutr. Biochem. 15, 210-219

Ahima R.S., Osei S.Y., 2001. Molecular regulation of eating behavior: new insights and prospects for therapeutic strategies. Trends Mol. Med. 7, 205-213

Askati H., Liu J., Dagogo-Jack S., 2005. Energy adaptation to glucocorticoid-induced hyperleptinemia in human beings. Metabolism 54, 876-880

Bhattachrya A., Lowrence R.A., Krishnan A., Zaman K., Sun D., Fernandes G., 2003. Effect of dietary n-3 and n- 6 oils and without food restriction on activity of antioxidant enzymes and lipids peroxidation in livers of cyclophosphamide treated autoimmune-prone NZB/W female mice. J. Amer. Coll. Nutr. 22, 388-399

Bueno A.A., Oyama L.M., de Oliveira C., Pisani L.P., Ribeiro E.B., Silveira V.L.F., do Nascimento C.M.O., 2008. Effects of different fatty acids and dietary lipids on adiponectin gene expression in 3T3-L1 cells and C57BL/6J mice adipose tissue. Eur. J. Physiol. 455, 701-709

Drevon C., 2005. Fatty acids and expression of adipokines. Biochim. Biophys. Acta 1740, 287-292

Dube M.G., Beretta E., Dhillon H., Ueno N., Kalra P.S., 2002. Central leptin gene therapy blocks high-fat diet-induced weight gain, hyperleptinemia, and hyperinsulinemia: increase in serum ghrelin levels. Diabetes 51, 1729-1736

Ellis J., Lake A., Hoover-Plow J., 2002. Monousaturated canola oil reduces fat deposition in growing female rats fed a high or low fat diet. Nutr. Res. 22, 609-621

Fasshauer M., Klein J., Neumann S., Eszlinger M., Paschke R., 2002. Hormonal regulation of adiponectin gene expression in 3T3-L1 adipocytes. Biochem. Biophys. Res. Commun. 290, 1084-1089

Flachs P., Mohamed-Ali V., Horakova O., Rossmeisl M., Hosseinzadech-Attar M.J., Hensler M., Ruzickova J., Kopecky J., 2006. Polyunsaturated fatty acids of marine origin induce adiponectin in mice fed a high-fat diet. Diabetologia 49, 394-397

Furukawa S., Fujita T., Shimabukuro M., Iwaki M., Yamada Y., Nakajima Y., Nakayama O., Makishima M., Matsuda M., Simomura I., 2004. Increased oxidative stress in obesity and its impact on metabolic syndrome. J. Clin. Invest. 114, 1752-1761

Garrido A., Garrido F., Guerra R., Valenzuela A., 1989. Ingestion of high doses of fish oil increases the susceptibility of cellular membrane to the induction of oxidative stress. Lipids 24, 833-835

Gronowska-Senger A., Pierzynowska J., 2002. Biological Food Evaluation (in Polish). SGGW Press, Warsaw, pp. 10-11

Ishida-Takahashi R., Uotani S., Abe T., Degawa-Yamauchi M., Fukushima T., Fujita N., Sakamaki H., Yamasaki H., Yamaguci Y., Eguchi K., 2004. Rapid inhibition of leptin signaling by glucocorticoids in Vitro and in Vivo. J. Biol. Chem. 279, 19658-19664

Katsuki A., Suematasu M., Gabazza E.C., Murashima S., Nakatani K., Togashi K., Yano Y., Adachi Y., Sumida Y., 2006. Increased oxidative stress is associated with decreased circulating levels of adiponectin in Japanese metabolically obese, normal-weight men with normal glucose tolerance. Diabetes Res. Clin. Pract. 73, 310-314 
Kim Y. J., Park T., 2008. Genes are differentially expressed in the epididymal fat of rats rendered obese by a high-fat diet. Nutr. Res. 28, 414-422

Oda N., Imamura S., Fujita T., Uchida Y., Inagaki K., Kakizawa H., Hayakawa N., Suzuki A., Takeda J., Hirikawa Y., Itoh M., 2008. The ratio of leptin to adiponectin can be used as an index of insulin resistance. Metabolism 57, 268-273

Orlando F.A., Goncalves C.G., George Z.M., Halverson J.D., Cunningham P.R., Meguid M., 2005. Neurohormonal pathways regulating food intake and changes after Roux-en-Y gastric bypass. Surg. Obes. Relat. Dis. 1, 486-495

Oudart H., Groscolas R., Calgari C., Nibbelink M., Leray C., Le Maho Y., Malan A., 1997. Brown fat thermogenesis in rats fed high-fat diets enriched with n-3 polyunsaturated fatty acids. Int. J. Obes. Relat. Metab. Disord. 21, 955-962

Peake P.W., Kriketos A.D., Denyer G.S., Campbell L.V., Charlesworth J.A., 2003. The postprandial response of adiponectin to a high-fat meal in normal and insulin-resistant subjects. Int. J. Obes. Relat. Metab. Disord. 27, 657-662

Pralong F.P., Gaillard R.C., 2001. Neuroendocrine effects of leptin. Pituitary 4, 25-32

Reeves P.G., 1997. Components of the AIN-93 diets as improvements in the AIN-76A diet. J. Nutr. $127,838 \mathrm{~S}-841 \mathrm{~S}$

Sadurskis A., Dicker A. Cannon B., Nedergaard J., 1995. Polyunsaturated fatty acids recruit brown adipose tissue: increased UCP content and NST capacity. Amer. J. Physiol.-Endocrinol. Met. 269, E351-E360

Saraswathi V., Gao L., Morrow J.D., Chait A., Niswender K.D., Hasty A.H., 2007. Fish oil increases cholesterol storage in white adipose tissue with concomitant decreases in inflammation, hepatic steatosis, and atherosclerosis in mice. J. Nutr. 137, 1776-1782

Soares A.F., Guichardant M., Cozzone D., Bernoud-Hubac N., Bouzaidi-Tiali N., Lagarde M., Géloën L.A., 2005. Effects of oxidative stress on adiponectin secretion and lactate production in 3T3-L1 adipocytes. Free Radical Biol. Med. 38, 882-889

Stachoń M., Fürstenberg E., Gromadzka-Ostrowska J., 2006. Effects of high-fat diets on body composition, hypothalamus NPY, and plasma leptin and corticosterone levels in rats. Endocrine 30, 69-74

Stachoń M., Gromadzka-Ostrowska J., Przepiórka M., Fürstenberg E., 2003. The effect of 3 or 6 weeks feeding of diets containing different fat source and content on deoxycorticosterone $11 \beta$ hydroxylase activity in adrenal gland and on plasma corticosterone and leptin concentration in rats. J. Anim. Feed Sci. 12, 617-631

Takahashi Y., Ide T., 2000. Dietary n-3 fatty acids affect mRNA level of brown adipose tissue uncoupling protein 1, and white tissue leptin and glucose transporter 4 in the rat. Brit. J. Nutr. $84,175-184$

Ukropec J., Reseland J.E., Gasperikova D., Demcakova E., Madsen L., Berge R.K., Rustan A.C., Klimes I., Drevon C.A., Sebökova E., 2003. The hypotriglyceridemic effect of dietary n-3 FA is associated with increased beta-oxidation and reduced leptin expression. Lipids 38, 1023-1029

Wang X., Quinn P.J., 1999. Vitamin E and its function in membranes. Prog. Lipid Res. 38, 309-336

Woods S.C., Benoit S.C., Clegg D.J., Seeley R.J., 2004. Regulation of energy homeostasis by peripheral signals. Best Pract. Res. Cl. En. 18, 497-515 